\title{
Dutch word stress as pronounced by Indonesian students
}

\author{
LILIE M. ROOSMAN
}

\begin{abstract}
This study focuses on the way in which the Dutch monophthongal vowels are pronounced by Indonesian students. To investigate whether Indonesian students realize the Dutch vowels correctly, especially when they are stressed, I analysed duration and quality of stressed and unstressed Dutch vowels. Measurements were done on the duration and the formant frequencies of the vowels spoken by Indonesian students and by native speakers of Dutch as well. Statistical analysis showed that in general the differences in duration between vowels spoken by the Indonesian students and by the native speakers were not significant. However, the effect of stress on the lengthening of the vowels was stronger for the Indonesian students than for the native speakers. In addition, statistical analysis of the formant frequencies confirmed that the non-native speakers realized the Dutch vowels slightly differently from the Dutch native speakers. The Indonesian students pronounced the stressed vowels more clearly than their unstressed counterparts; yet their vowel diagram is smaller than the vowel diagram of the native speakers.
\end{abstract}

KEYWORDS

Dutch word stress, vowel duration, vowel quality, and non-native speech.

\section{INTRODUCTION ${ }^{1}$}

People who learn a foreign language after the age of puberty may use the melody and rhythm of their first language while speaking the foreign language (Chun 2002: xiii). Research shows that influence from the first language on the foreign language can be heard in the pronunciation of the vowels, but

1 I thank Dr Ellen van Zanten for her comprehensive and constructive comments at various stages of this article; and Professor Hein Steinhauer for his comments and suggestion on an earlier version

LILIE ROOSMAN is a lecturer at Dutch Studies Program and Linguistic Department of the Faculty of Humanities, University of Indonesia, Jakarta. She took her PhD in Experimental Phonetics at Leiden University in 2006. In December 2009 she will start her postdoc research on "Word segmentation in non-stress languages", a grant from KNAW, Scientific Programme Indonesia-Netherlands (SPIN) Postdoc Programme. E-mail: lilieroosman@yahoo.co.uk.

(C) 2009 Fakultas Ilmu Pengetahuan Budaya, Universitas Indonesia 
also in the prosody, in particular the rhythm and the melody. Therefore it would seem interesting to investigate how Indonesian students of the Dutch Studies Program at University of Indonesia pronounce Dutch. I would like to know to what extent the influence of Indonesian can be heard in the way these students speak Dutch. In particular, is their realisation of Dutch stress influenced by the prosody of their own native language?

For most Indonesian students the stress system of Dutch is difficult to acquire. Stress is a distinctive feature in Dutch. Two Dutch words may have the same sequence of consonants and vowels but differ in stress position. In Indonesian, on the other hand, word stress does not exist. For that reason, the realization of Dutch stress by Indonesian students is expected to differ from that of native speakers of Dutch.

There are four parameters of stress, namely pitch, duration, loudness and vowel quality. Stressed syllables may have longer duration, higher pitch, greater loudness and more carefully articulated vowel and consonant sounds than unstressed syllables.

This research considers the realization of Dutch word stress by Indonesian speakers with a focus on the duration and the quality of the stressed vowels. I will investigate whether Indonesian students of Dutch are able to pronounce the Dutch monophthongal vowels correctly when they occur in stressed syllables (as compared to unstressed syllables), leaving aside the question whether the stress is on the correct syllable. The results may have implications for the teaching of Dutch to Indonesian students.

\section{THEORETICAL BACKGROUND}

For Indonesian students, speaking Dutch is difficult when they have no previous knowledge of the language. The most difficult thing they must acquire is word stress. Stress is an abstract linguistic property of a word that defines the position of the most prominent syllable in the word. In languages such as English and Dutch, the stressed syllable is articulated with greater effort than its unstressed counterpart, usually with higher tone and a longer vowel (Ladefoged 1982: 104).

For speakers of non-stress languages, stress is obviously an unfamiliar feature. Although they may emphasize parts of their speech in a superficially similar way as the speakers of a stress language do, they may still have difficulties in acquiring the correct realisation of such emphasis. Indonesian is a so-called non-stress language. Stress is not a distinctive feature in Indonesian. However, there is always one word in an utterance that is accented (Moeliono and Dardjowijdojo 1988). Whichever syllable of an Indonesian word is emphasized, the meaning of the word is always the same. For that reason, Indonesian students are not sensitive to Dutch word stress. In less careful speech, they are likely to make mistakes in putting the stress in the correct position. Furthermore, they realize the stress differently. Lilie Roosman (2006) showed that native speakers of Indonesian had difficulties in producing and identifying Dutch word stress correctly. However, on the 
phrasal level Indonesian does have emphasis: usually, one syllable of the phrase is stronger than the others. In an acoustical analysis of Betawi Malay, a Malay dialect that has similar prosodic characteristics as Indonesian, Roosman (2006) demonstrated that this accent is realized by a strong lengthening of the accented vowel.

Another problem that occurs in acquiring a foreign language is the correct realization of the phonemes (vowels and consonants). Differences in phoneme inventories between the mother language and the foreign language influence the ability to speak the foreign language (Van Wijngaarden 2001: 110-112; Wang 2007: 120-121; see also Roosman 2006: 94-96).

Dutch and Indonesian indeed have different vowel inventories. Dutch has thirteen monophthongal phonemes (Kooij and Van Oostendorp 2003), as well as three diphthongs: $u i$ /œy/, ei or $i j / \varepsilon I /$, and $a u$ or ou / $\alpha u /$, and a number of marginal vowel phonemes that I did not study in this experiment. Dutch vowels can also be categorised in tense (long: /i/, / e/, /a/, /o/, /u/, $/ \mathrm{y} /$, and $/ \varnothing /$ ) and lax (short: /I/, / $/, / \alpha /, / \rho /, / \propto /$, and /ə/) vowels. Figure 1 summarizes the vowel inventory (monophthongs only) of Dutch after Verhoeven and Van Bael (2002). In this figure Dutch vowels are defined by F1 (the first formant, corresponding to the degree of mouth opening) and F2 (the second formant, reflecting 'front' and 'back' articulation), based on the study done by Pols, Tromp, and Plomp (1973). The schwa vowel /ə/ is not defined in Figure 1 and the lax vowel / $œ /$ is indicated by the symbol y.

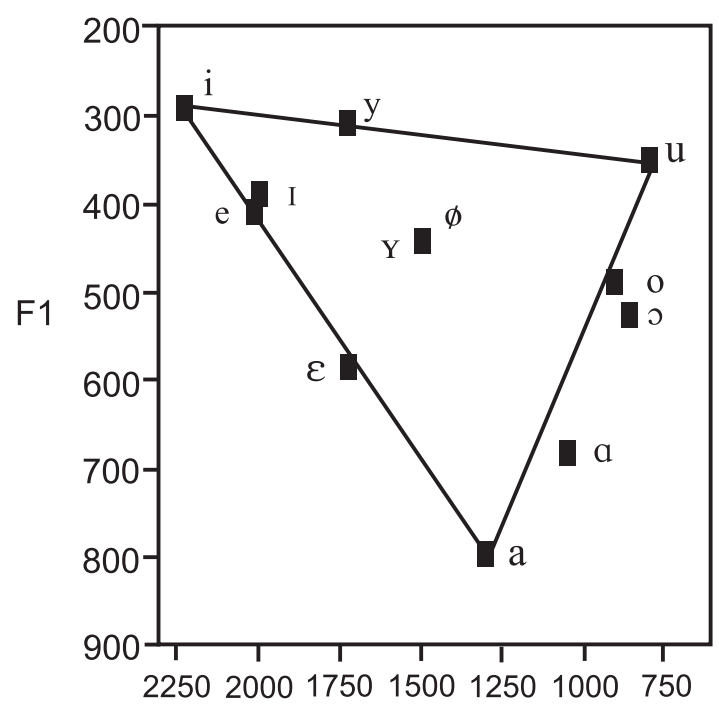

F2

Figure 1 Dutch vowel inventory (Verhoeven and Van Bael 2002)

Indonesian, on the other hand, has only six monophthongal phonemes (Muslich 2008:95). Different tense-lax (long-short) categories do not exist in Indonesian. Table 1 summarizes the vowel inventory of Indonesian. 


\begin{tabular}{|l|lll|}
\hline & Front & Center & Back \\
\hline High & $/ \mathrm{i} /$ & & $/ \mathrm{u} /$ \\
Mid & $/ \mathrm{e} /$ & $/ ə /$ & $/ \mathrm{o} /$ \\
Low & & & $/ \mathrm{a} /$ \\
\hline
\end{tabular}

Table 1. Indonesian vowel inventory

However, this does not mean that there are no differences at all between tense and lax pronunciations of vowel segments in Indonesian. Usually, (disyllabic) words ending in a consonant are pronounced with lax vowels, whereas words ending in a vowel tend to have tense vowels. For instance,

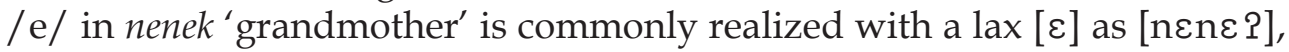
but in sore 'afternoon, early evening' /e/ is realized with a tense [e] as [sore]. Similarly, /i/ is usually pronounced tense in kiri [kiri] 'left' and lax in listrik [listrik] 'electrics, electricity'. It is however acceptable to pronounce these words as [desa], [nene?], [kIrI], and [listrik], though they may sound unusual. Contrary to Dutch, tense-lax articulations are phonologically irrelevant in Indonesian.

For these reasons, it will be interesting to investigate the realization of Dutch stressed vowels by Indonesian students. Vowels in stressed syllables are generally realized more clearly and longer than the same vowels in unstressed syllables. Therefore, I studied the duration and the frequencies of the first and second formant of the vowels to investigate to what extent Indonesian students realize Dutch vowels in stressed syllables correctly.

\section{METHOD}

Three (one male, two female) students of the fourth semester at the Dutch Studies Program, University of Indonesia, took part in a production experiment. All speakers were late bilinguals; they started to learn Dutch after the age of puberty.

The experiment made use of dialogues from the Dutch course book Help 2 (Ham, Tersteeg, and Zijlmans 2005) that is used as teaching material at the University of Indonesia. The speakers acted sixteen short dialogues from that book. All dialogues were presented to the speakers on sheets of paper, without any indication of the position of the stress on the words. They produced altogether 546 monophthongal vowels. The dialogues were recorded in a quiet room onto a digital voice recorder. For comparison, the same dialogues spoken by four Dutch natives (two males, two females) were used. Of these, 195 tokens were used in the statistical analyses. Altogether, 741 vowel tokens were investigated in this experiment.

For the analyses, the monophthongal vowels were segmented and measured by hand with PRAAT speech processing software (Boersma and Weenink 1996). The segment boundaries were stored in so-called Praat TextGrids. Durations of the time intervals between successive segment boundaries and the first and second formant (F1, F2) frequencies were then 
automatically determined by the Praat speech analysis software.

\begin{abstract}
ANALYSIS
Statistical analyses were first performed with vowel duration, and F1 and F2 values as test variables to see whether there were any significant differences between native and non-native speakers. An analysis of variance showed that the effect of nativeness was not significant for vowel duration $(F=0.97, p=$ 0.325). Regarding vowel quality, effects of nativeness only occurred highly significantly for F1 (degree of mouth opening; $F=10.82, p<0.001$ ) but not for F2 (front $\sim$ back articulation; $F=1.71, p=0.354$ ). I will present the results of the vowel duration analysis first, followed by the results of the formant analyses. For each analysis a comparison between native and non-native speakers was made.

The durational analysis of the Dutch monophthongs was carried out in non-final position only, to reduce the effect of 'final lengthening': all else being equal, word-final segments are pronounced more slowly than segments occurring earlier in the word. Final lengthening may interfere with stressrelated lengthening (Cambier-Langeveld 2000). The duration (in milliseconds) of each vowel token was stored in a database for off-line statistical analysis. Of each vowel, at least five tokens were analysed. To investigate whether there were significant differences in duration between the thirteen vowel phonemes and between realizations in stressed and unstressed syllables, a univariate analysis of variance then was performed with the duration of the vowels as dependent variable.
\end{abstract}

Acoustical analyses were executed for the formants of the monophthongal vowels in all positions in the word. The F1 and F2 values of each vowel token were stored in the database for off-line statistical analysis. An analysis of variance was performed with mean F1 and mean F2 values as dependent variables, broken down by vowel type, and stress condition as an independent variable. As indicated above, significant differences were found between the native and non-native speakers for the F1 and the F2 values. Therefore, statistical analyses were first designed for the native speakers, followed by analyses for the non-native speakers.

\title{
RESULTS AND DISCUSSION
}

\section{VOWEL DURATION}

Native speakers. Before we turn to the duration analysis of the non-native speakers, we will first consider the duration analysis of the native speakers. The univariate analysis of variance shows a significant effect of stress with $\mathrm{F}(1,88)=17.83, \mathrm{p}<0.001$, and vowel type with $\mathrm{F}(12,88)=3.29, \mathrm{p}=0.001$ on the mean duration of the vowels. However, the combined effect of stress and vowel type is not significant $(\mathrm{p}=0.267)$. There is no significant effect of gender $(p=0.869)$ on the mean vowel durations; therefore it is not necessary to make a distinction between the male and the female native speakers. Figure 
2 presents the vowel durations of the native speakers. ${ }^{2}$

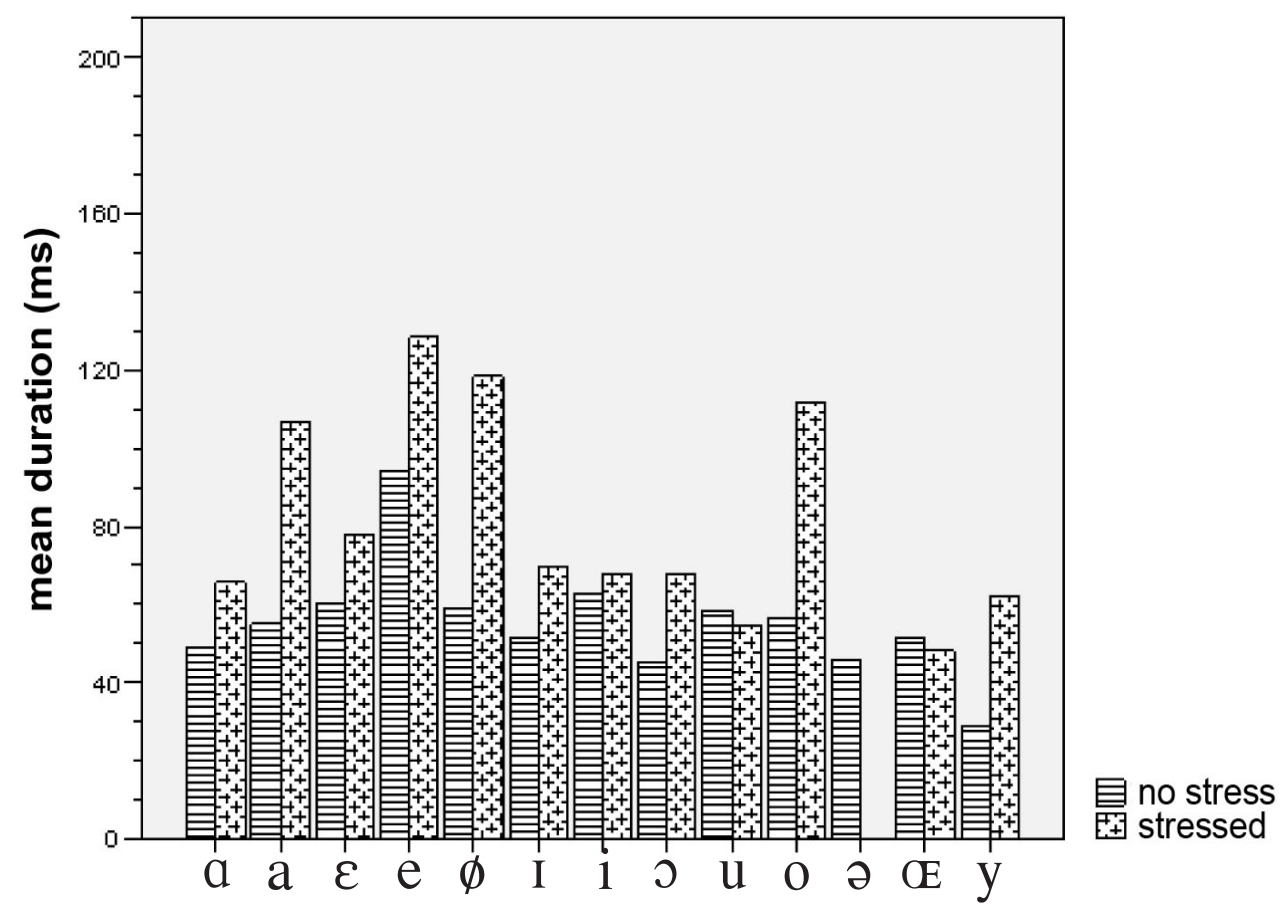

Figure 2. Mean duration of the Dutch monopthongs as spoken by four Dutch Speakers in stressed and unstressed syllables.

Figure 2 shows that the schwa vowel /ə/ is never stressed by the Dutch speakers. Secondly, in most cases, the stressed vowels are longer than their unstressed counterparts are. Actually, the tense vowels $/ a, \varnothing, 0, y /$ are in stressed syllables approximately twice as long as in unstressed syllables. However, in two cases the reverse occurs: / $\mathrm{u} /$ and / / are (slightly) longer in unstressed syllables. This shows that stress in Dutch is not merely realized by vowel lengthening. Pitch, intensity, and vowel quality are also correlates of stress (Van Heuven 2002: 13). The last parameter, vowel quality, will be presented in the next paragraph. Finally, tense vowels are on average realized longer than their lax counterparts are. This is in line with the realization of Dutch vowels as described by Rietveld and Van Heuven (1997: 234). Four tense-lax pairs differ significantly $(/ \mathrm{e} /-/ \varepsilon /$ with $\mathrm{p}=0.003 ; / \mathrm{a} / \mathrm{-} / \mathrm{\alpha} /$ with $\mathrm{p}$

2 Figure 2 reveals some effect of the degree of mouth opening in vowel realization: the larger the degree of opening - and consequently the articulatory movement - the longer the vowel (Lehiste 1970: 18-19). For instance, the high vowels /i/ and / $\mathrm{u} /$ are, as expected, relatively short, and the low vowel /a/ is comparatively long. The mid vowels /e/ and /o/, however, are longer than predicted. Similar effects appear in Figure 2. This may have been caused by the fact that the consonantal context was not identical for all vowels. However, for a similar patterning of Indonesian vowel duration see Van Zanten (1989: 18-21). 
$=0.007 ; / \varnothing /-/ \propto /$ with $\mathrm{p}=0.009 ;$ and $/ \mathrm{o} /-/ \mathrm{o} /$ with $\mathrm{p}=0.011)$. Whenever length is a distinctive feature in a language in which there are long and short vowels distinguished by length, duration has little value to the stress/nostress distinction (Berinstein 1979: 46).

Non-native speakers. A similar univariate analysis of variance was done for the non-native speakers with mean vowel duration as a dependent variable broken down by stress condition, vowel type, and sex of speaker. The result of the univariate tests shows that the effect of stress on vowel duration is highly significant with $F(1,348)=31.88, p<0.001$, and the same holds for the effect of vowel type with $F(12,348)=9.13, p<0.001$. However the Tests of Between-Subject effects indicate that the combined effect of stress and vowel type is not significant $(\mathrm{F}(12,348)=1.10, \mathrm{p}=358)$. Moreover, the effect of gender on the vowel duration is not significant. Like with the native speakers, further analysis of the difference between male and female speakers was not considered necessary.

Figure 3 illustrates the mean Dutch vowel durations (in milliseconds) as spoken by the three Indonesian students, in stressed and unstressed condition.

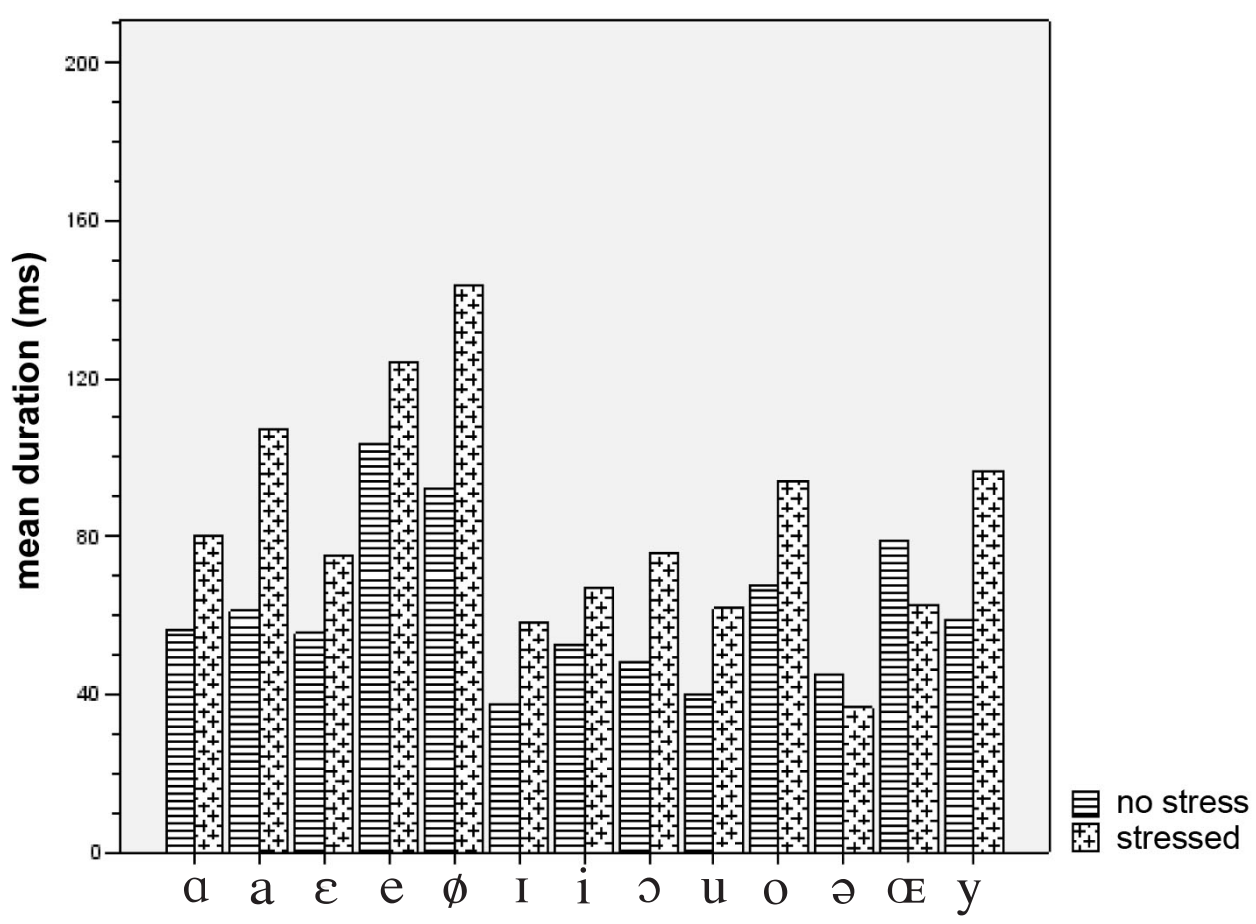

Figure 3. Mean duration of the Dutch monopthongs spoken by three Indonesian students (one male and two females) in stressed and unstressed syllables

Figure 3 shows that like the native Dutch speakers, the non-native Indonesian speakers realized the stressed vowels generally longer than the unstressed 
vowels. There are again two exceptions: the schwa vowel /ə/ and the lax vowel / $œ /$. These two vowels were on average longer in unstressed syllables than in stressed syllables. The schwa /ə/ is normally unstressed in Dutch. The Indonesian speakers put in fact the stress in two instances incorrectly on the schwa: the unstressed / $ə /$ in (non-prominent) hem "him" was accented and the word donderdag 'Thursday' got stress on the penultimate /ə/ syllable instead of on the (correct) antepenultimate syllable. The lax rounded vowel $u / œ /$ as in $n u t$ "benefit" does not really exist in Indonesian, so I assume that the speakers confused it with another rounded vowel that does exist in their language, namely the tense $/ \mathrm{u} /$ or $/ \mathrm{o} /$. Actually, the Indonesians realized the unstressed $/ \mathrm{u} /$ considerably shorter than the Dutch speakers did.

Tense vowels were, for the Indonesian subjects also, in most cases longer than lax vowels. This is in line with the typical realization of Dutch vowels by native speakers (Rietveld and Van Heuven 1997: 234). Pairwise Comparisons show that the differences are only significant in three tense-lax pairs $(/ \mathrm{a} / \mathrm{-} / \mathrm{\alpha} /$ $\mathrm{p}=0.003, / \mathrm{e} /-/ \varepsilon / \mathrm{p}<0.001$ and $/ \varnothing /-/ \propto /(\mathrm{p}<0.001)$. Notice, however, that tense $/ \mathrm{u} /$ is realized shorter than lax / /. Finally, unlike the Dutch results, the difference between /o/ and / / is not significant (compare Rietveld and Van Heuven 1997: 234).

Comparison of native and non-native speakers. Comparing the figures of the mean vowel durations of the native speakers (Figure 2) with that of the non-native speakers (Figure 3), our Indonesian subjects seem, like the Dutch subjects, to be able to differentiate between the realizations of stressed and unstressed vowels. The effect of stress on vowel duration was similar for both groups of subjects. Moreover, the typical differences in length between tense and lax vowels also occur in our non-native data. It is also born out by the independent $t$-test that the effect of nativeness was insignificant ( $p$ value 0.325 ). Significant differences between native and non-native speakers only occur in the unstressed condition of the vowels / I/ $(\mathrm{F}(1,25)=5.57$, p $=0.026)$ and $/ \propto /(F(1,7)=9.53, p=0.018)$. The non-native speakers realized the unstressed / I/ significantly shorter than the native speakers did. The unstressed / / produced by the non-native speakers was significantly longer than that produced by the native speakers.

Table 2 sums up the percentages of the lengthening of the stressed vowels. The table shows that the overall accentual lengthening is in general greater by the non-native speakers than by the native speakers. The only exception is the lengthening of the /o/ $(o o)$ this vowel is lengthened more by Indonesian speakers than by Dutch speakers when stressed. This finding is in line with the finding indicated in Roosman (2006: 133) for Betawi Malay, an Indonesian vernacular with similar prosodic characteristics as Indonesian.

\section{VOWEL QUALITY}

Native speakers. A multivariate analysis of variance for the native speakers' data was carried out with F1 and F2 in the dependent list broken down by 
stress condition and vowel type. The combined effects of stress and vowel type were not significant for $F 1(F(11,170)=0.838, p=0.603)$ and $F 2(F$ $(11,170)=1.380, p=0.186)$. However, there was a significant effect of stress for $F 1$ with $F(1,170)=8.123, p=0.005$, though not for $F 2(F(1,170)=3.249$, p, 0.073). Figure 4 illustrates the mean F1 and F2 values of the Dutch vowels spoken by native speakers in stressed (dark circle) and unstressed (light circle) condition. Spelling notation is used to indicate the tense $(a a, i e, u u$...) and the lax $(a, i, u$...) vowels.

The formant values of the Dutch vowels in Figure 4 are similar to those found by Pols (1977) and Van Bergem (1993), both cited in Rietveld and Van Heuven $(1997:$ 133, 188).

\begin{tabular}{|l|l|l|}
\hline & & \\
Vowel & native & non-native \\
\hline$/ \mathrm{a} /$ & 52.56 & 66.54 \\
\hline$/ \mathrm{a} /$ & 88.86 & 93.99 \\
\hline$/ \varepsilon /$ & 16.34 & 21.68 \\
\hline$/ \mathrm{e} /$ & 67.56 & 85.79 \\
\hline$/ \varnothing /{ }^{*}$ &. & 55.98 \\
\hline$/$ I/ & 17.61 & 39.47 \\
\hline$/ \mathrm{i} /$ & -2.71 & 16.08 \\
\hline$/ \mathrm{J} /$ & 31.21 & 76.48 \\
\hline$/ \mathrm{u} /$ & -3.09 & 26.18 \\
\hline$/ \mathrm{o} /$ & 98.42 & 39.52 \\
\hline$/$ /ə** &. & -23.54 \\
\hline$/ \propto /$ & -29.41 & -19.63 \\
\hline$/ \mathrm{y} /$ & 113.79 & 148.66 \\
\hline & 38.37 & 47.97 \\
\hline
\end{tabular}

Note

* One condition of the / $\varnothing /$ is missing due to the lack of data. ** /ə/ no data of the stressed condition.

The minus value means that the stressed vowel is shorter.

Table 2. Percentage of stress related lengthening by the native and the non-native speakers for each vowel separately and for all vowels together

Figure 4 shows that the Dutch speakers realized the vowels to a certain extent less centralized in stressed condition than in unstressed condition. A one-way analysis of variance split into vowel type was performed with the mean F1 and F2 values in the dependent list broken down by stress condition as independent variable. The result shows that the stress effect is significant for the F1 of the vowels / a/ ( $a a$ in Figure 3; $F(1,22)=5.00, p=0.036$ ) and $/ \varepsilon$ / $(e ; \mathrm{F}(1,16)=5.53, \mathrm{p}=0.032)$. Effects of stress are almost significant for the F1 of / / $(o ; \mathrm{p}=0.054), / \mathrm{I} /(i ; \mathrm{p}=0.063)$, and / $\mathrm{\alpha} /(a ; \mathrm{p}=0.066)$. The Dutch native speakers realized the stressed /a/, / $\varepsilon /, / \rho /, / I /$, and / $\alpha /$ with a lower tongue position than the unstressed counterparts. Effects of stress on the F2 are highly significant for the tense /e/ $(e e ; \mathrm{F}(1,21)=13.48, \mathrm{p}=0.001)$ and almost significant for the lax $/ \varepsilon /(e ; \mathrm{p}=0.068)$. Figure 4 also shows that unstressed 
/e/ (ee) and $/ \varepsilon /(e)$ were rather close to the schwa vowel / $/$ /. The extreme dissimilarity between the $\mathrm{F} 2$ 's of stressed and unstressed $u / œ /$, as illustrated in Figure 4, is accidental $(\mathrm{F}<1)$ and due to the small amount of data.

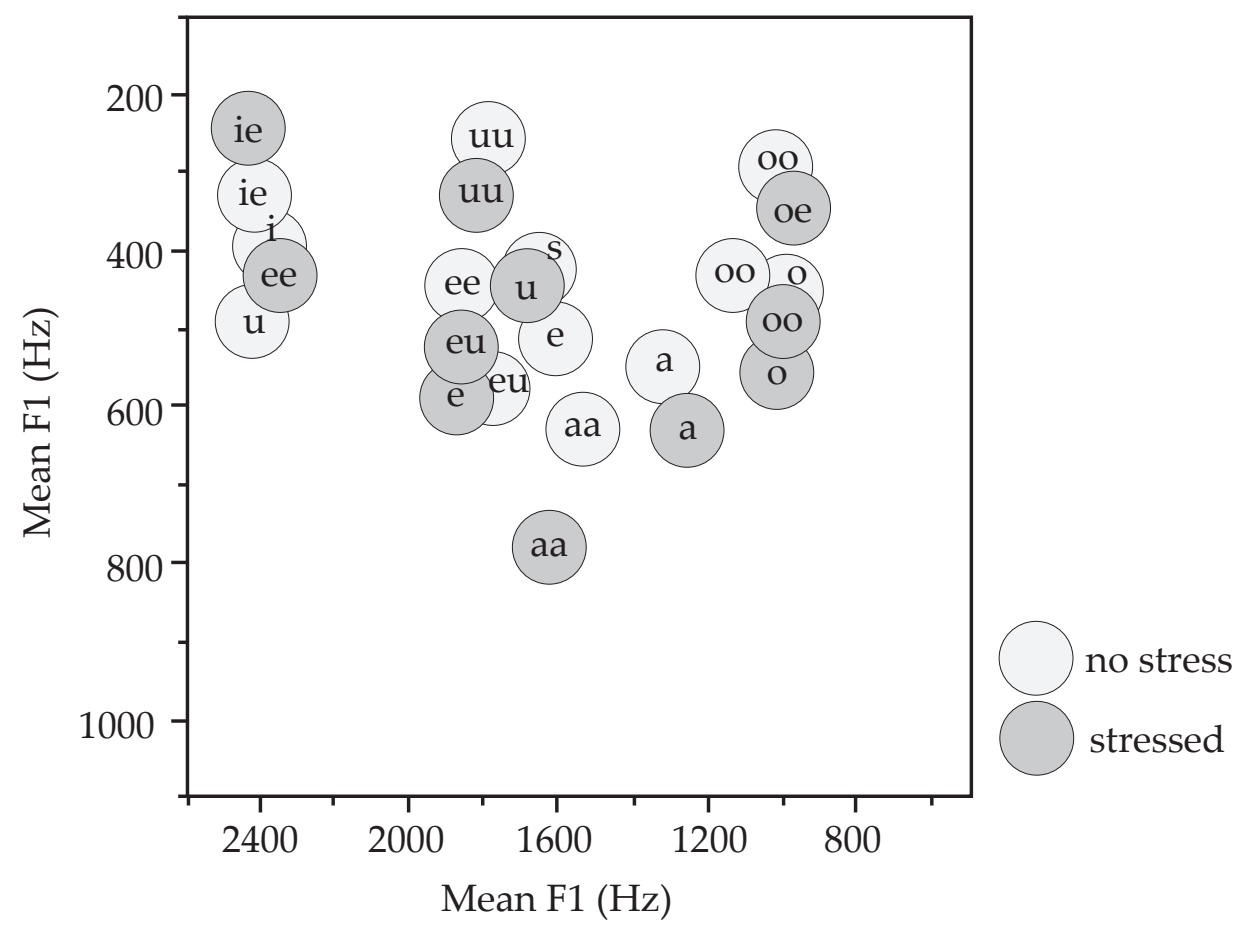

Figure 4. Scatterplot of mean F1 and F2 values of Dutch monophthongs in stressed and unstressed condition, spoken by four Dutch speakers (two males and two females). The letter s symbolized the schwa /ə/.

Non-native speakers. Vowel quality analysis of the non-native speakers starts with the analysis of the effect of stress on the F1 and F2 of the Dutch vowels as spoken by the three subjects. The results show that the effects of vowel type and stress condition together are highly significant for F1 and F2 with $p$ $<0.001$. However, the effect of stress alone is not significant, given that a oneway ANOVA shows insignificant effects of stress with $F(1,545)=1.942, p=$ 164 for $F 1$ and $F(1,545)=0.151, p=698$ for F2. The vowel triangle of the Dutch monophthongs spoken by the Indonesian subjects is illustrated in Figure 5.

Figure 5 shows a scatterplot of the Dutch monophthongal vowels as spoken by all three Indonesian subjects taken together. The spelling of the vowels is the same as in Figure 4. The dark circles represent the stressed vowels and the light circles the unstressed vowels. In most cases, the dark circles of the stressed tokens are situated near the edge of the figure; most vowels are articulated more carefully if they are stressed. Their unstressed counterparts tend to be closer to the central vowel, the schwa / ə/. However, a minority, namely the tense vowels /u/, /ø/ and /y/ (oe, eu, uu in Figure 5) behave differently, 
although the stressed and unstressed $/ \mathrm{u} /(o e)$ realizations are very close to each other; the F1 and F2 values for both stressed and unstressed / $\mathrm{u} /$ are similar. $/ \varnothing /$ and /y/ (eu and $u u$ in Figure 5) are probably the most difficult vowels for Indonesian students. The front rounded / y / $(u u)$ is realized with a higher $\mathrm{F} 1$ value when stressed, indicating a greater mouth opening. Moreover, /y/ becomes as backward as the central vowel when it is unstressed. Finally, the stressed lax vowel / I / (i) has a lower F1, thus higher tong position, than its unstressed counterpart, but it is less to the front on the F2 axis. I carried out a one-way analysis of variance split into the different vowels, with the F1 and F2 variables as the test variables and stress condition as the factor variable. The result indicates that the effect of stress was overall insignificant. Small effects did, however, occur as regards the $\mathrm{F} 1$ of /i/ (ie in Figure $4 ; \mathrm{F}=2.88$, $\mathrm{p}$ value 0.099$)$, and $/ \varepsilon /(e ; \mathrm{F}=3.45$, $\mathrm{p}$ value 0.070$)$ and on the $\mathrm{F} 2$ of $/ \varepsilon /(e ; \mathrm{F}$ $=3.36, \mathrm{p}=0.074)$ and $/ \mathrm{o} /(o o ; \mathrm{F}=2.90, \mathrm{p}=0.098)$. As illustrated in Figure 5, stressed ie was articulated with a lower F1, hence higher tong position, while $e$ was articulated with a higher F1, hence greater mouth opening than their unstressed counterparts. The front vowel $e$ was pronounced more forward, while the back rounded vowels, oo, was pronounced more backward when stressed.

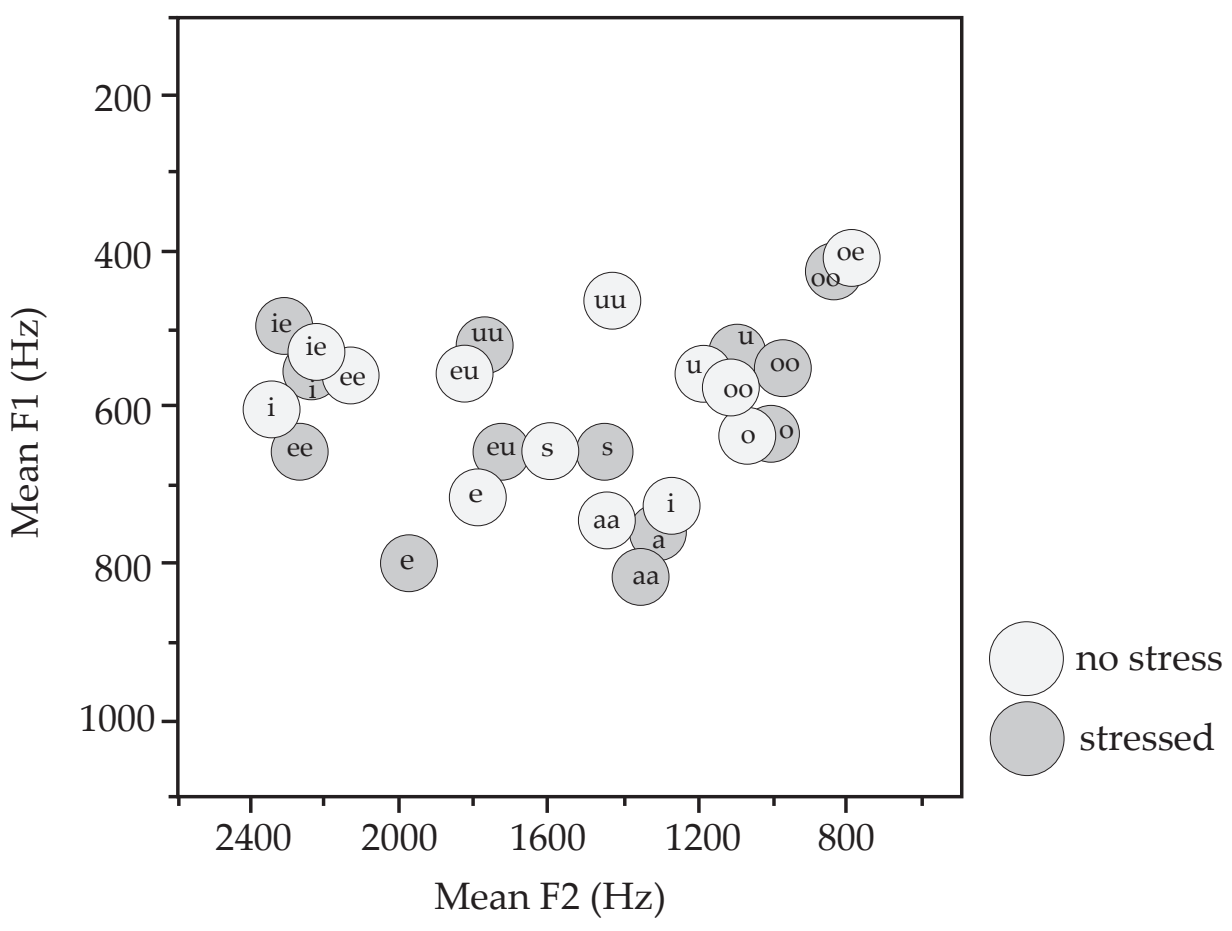

Figure 5. Scatterplot of the Dutch monophthongs in stressed and unstressed condition, spoken by three Indonesian students (one male and two females). The letter s symbolized the schwa /ə/. 
Comparison of native and non-native speakers. To investigate whether the nonnative speakers realized the stressed monophthongal vowels in the same way as the native speakers, a one-way ANOVA split into the stress conditions was carried out to test the effects of nativeness on the F1 and F2 values of the vowels. The result shows that highly significant effects occur for F1 in both conditions, with $\mathrm{F}(1,395)=57.746, \mathrm{p}<0.001$ in stress condition and $\mathrm{F}$ $(1,342)=167.646, p<0.001$ in unstressed condition. No significant effects are found for F2 in both conditions ( $\mathrm{F}<1$ in stressed and unstressed condition). Subsequently, a similar one-way ANOVA was executed for the stressed condition only, split into vowel type. The outcome demonstrates significant differences in vowel qualities between the native and non-native speakers as illustrated in Table 3.

\begin{tabular}{|c|c|c|c|c|c|c|c|c|c|c|}
\hline \multirow[t]{3}{*}{ vowel } & \multicolumn{5}{|c|}{ Stressed condition } & \multicolumn{5}{|c|}{ Unstressed condition } \\
\hline & \multirow[t]{2}{*}{$\mathrm{df}$} & \multicolumn{2}{|c|}{ F1 } & \multicolumn{2}{|c|}{ F2 } & \multirow[t]{2}{*}{ df } & \multicolumn{2}{|c|}{ F1 } & \multicolumn{2}{|c|}{$\mathrm{F} 2$} \\
\hline & & $\mathrm{F}$ & Sig. & $\mathrm{F}$ & Sig. & & $\mathrm{F}$ & Sig. & $\mathrm{F}$ & Sig. \\
\hline $\mathrm{a} / \mathrm{a} /$ & $(1,56)$ & 8.222 & 0.006 & 0.594 & 0.444 & $(1,102)$ & 43.452 & 0.000 & 0.275 & 0.601 \\
\hline aa /a/ & $(1,53)$ & 0.629 & 0.431 & 9.295 & 0.004 & $(1,24)$ & 4.343 & 0.048 & 0.154 & 0.698 \\
\hline $\mathrm{e} / \varepsilon /$ & $(1,34)$ & 17.634 & 0.000 & 0.765 & 0.388 & $(1,40)$ & 44.029 & 0.000 & 7.845 & 0.008 \\
\hline $\mathrm{ee} / \mathrm{e} /$ & $(1,49)$ & 39.386 & 0.000 & 0.333 & 0.566 & $(1,22)$ & 36.556 & 0.000 & 0.686 & 0.416 \\
\hline $\mathrm{eu} / \varnothing /$ & $(1,50)$ & 0.752 & 0.425 & 0.377 & 0.566 & $(1,4)$ & 1.019 & 0.370 & 1.634 & 0.270 \\
\hline $\mathrm{i} / \mathrm{I} /$ & $(1,51)$ & 15.168 & 0.000 & 0.475 & 0.494 & $(1,70)$ & 63.735 & 0.000 & 0.985 & 0.324 \\
\hline $\mathrm{ie} / \mathrm{i} /$ & $(1,24)$ & 42.236 & 0.000 & 0.478 & 0.496 & $(1,42)$ & 83.040 & 0.000 & 3.783 & 0.058 \\
\hline $0 / 0 /$ & $(1,30)$ & 3.265 & 0.081 & 1.895 & 0.179 & $(1,54)$ & 31.275 & 0.000 & 6.917 & 0.011 \\
\hline oe $/ \mathrm{u} /$ & $(1,22)$ & 18.938 & 0.000 & 0.691 & 0.415 & $(1,12)$ & 16.451 & 0.002 & 0.209 & 0.655 \\
\hline $00 / 0 /$ & $(1,34)$ & 3.086 & 0.088 & 0.680 & 0.415 & $(1,24)$ & 15.844 & 0.001 & 0.319 & 0.577 \\
\hline \multicolumn{2}{|c|}{ schwa /ə/ } & & & & & $(1,238)$ & 162.907 & 0.000 & 0.020 & 0.887 \\
\hline $\mathrm{u} / œ /$ & $(1,6)$ & 0.101 & 0.762 & 7.474 & 0.034 & $(1,18)$ & 12.399 & 0.002 & 2.201 & 0.155 \\
\hline $\mathrm{uu} / \mathrm{y} /$ & $(1,6)$ & 3.774 & 0.100 & 0.047 & 0.836 & $(1,12)$ & 5.319 & 0.040 & 0.487 & 0.498 \\
\hline
\end{tabular}

Table 3. ANOVA table of significances; differences between the realizations by the native and the non-native speakers of F1 and F2 of the Dutch vowels in stressed and unstressed condition.

Data for the schwa vowel $(/ ə /)$ do not exists in stressed condition because the schwa is never stressed by native speakers of Dutch. Significant differences between the non-native and the native speakers occur as regards the $\mathrm{F} 1$ of the stressed / $/$ /, / $\varepsilon /, / \mathrm{e} /, / \mathrm{I} /, / \mathrm{i} /$, and /u/. Non-native speakers pronounced these vowels when stressed with significantly higher $\mathrm{F} 1$, indicating greater mouth opening, than the native speakers did. On the F2 axis, significant differences between the native and non-native speakers only occur for stressed /a/ and / $œ /(a a$ and $u$ ). Non-native speakers articulated stressed $a a$ and $u$ further back in the oral cavity than the native speakers. All the other stressed vowels were pronounced by the non-native speakers with similar F2 values 
as were pronounced by the native speakers.

On the other hand, stronger significances occur for the F1 in unstressed conditions. The non-native speakers realized almost all unstressed vowels significantly more open than the native speakers did. Only the degree of openness of $/ \varnothing /$ of the non-native speakers was similar to that of the native speakers. The front-back distinction (the position on the F2 axis), was less problematic for the non-native speakers. Significant differences only occur for $/ \varepsilon /$ and $/ \rho /$ that were realized more forward by the Indonesians.

When we compare Figures 4 and 5, we notice that the vowel triangle of the native Dutch speakers (Figure 4) is considerably larger than that of the non-native speakers (Figure 5). In Figure 4, the F1 values of the close vowels / i, y, u/ (ie, uu and oe) are around 250-300 Hz, whereas in Figure 5 these values are between 400 and $500 \mathrm{~Hz}$. Also, the front vowels /i/ and / e/ (ie and ee) in Figure 4 have considerably higher F2 values than those in Figure 5. As regards the open vowel, /a/ (aa), there does not seem to be much difference between the F1 values in both figures, nor is the spreading on the F2 axis very different. The smaller vowel triangle of the non-native speakers suggests that their native language, which has only six vowel phonemes and, consequently, a smaller vowel triangle, influences the pronunciation of these speakers. A similar effect was found by Van Zanten (1989). In this research, Indonesians with a Sundanese background used a larger vowel space than Toba Batak speakers, with the size of the Javanese vowel space in between these two. This could be explained by taking into account the vowel systems: Sundanese has seven vowels, Javanese six, and Toba Batak five.

However, I suspected that the differences were partly caused by gender: the native Dutch speakers consisted of two males and two females, whereas the Indonesian speakers included only one male, and two females. Thus, corresponding to the analysis of the native speakers' data, an analysis of variance was performed with the mean F1 and F2 as the dependent variables broken down by gender to investigate whether there are significant differences between the male and female non-native speakers. The result shows that the effect of speaker sex is highly significant for the F1 values with F (1.544) $=34.95, \mathrm{p}<0.001$, but not for the F2 values $(\mathrm{F}(1.544)=2.02, \mathrm{p}=0.156)$. The female non-native speakers realized the mid and low vowels, like /e/ and /a/, with a significantly higher F1, thus more open, than the male non-native $\mathrm{did}$. There are no significant differences in terms of front-back articulation. The following figures (Figures 6a and 6b) display the scatterplots of the male and female native speakers separately. The same spelling notations as for Figure 4 are used to refer to the tense (two letters $a a, e e$, oo ...) and the lax vowels (single letter $a, e, o \ldots$ ).

A one-way ANOVA split into stress condition was executed. Significant differences occur for the F1 of $a a(/ \mathrm{a} /, \mathrm{p}=0.004), a(/ \mathrm{a} /, \mathrm{p}=0.001), i(/ \mathrm{I} /, \mathrm{p}$ $=0.005), e e(/ \mathrm{e} /, \mathrm{p}=0.019)$, and $e(/ \varepsilon /, \mathrm{p}=0.001)$; and in one vowel the $u u$ for the F2, with $\mathrm{p}=0.025$. The female non-native speakers had a difficulty in producing the front rounded $u u$. They pronounced that vowel backward in 
the oral, cavity. However, compared to figure 4, the non-native male speaker realized the $u u$ too much forward. The vowel space of the female non-native speakers (Figure 6b) is indeed larger than that of the male non-native speaker (Figure 6a). It is, however, considerably smaller than the vowel space of the native Dutch speakers (Figure 4). In particular, the Dutch speakers differentiated more as regards openness.

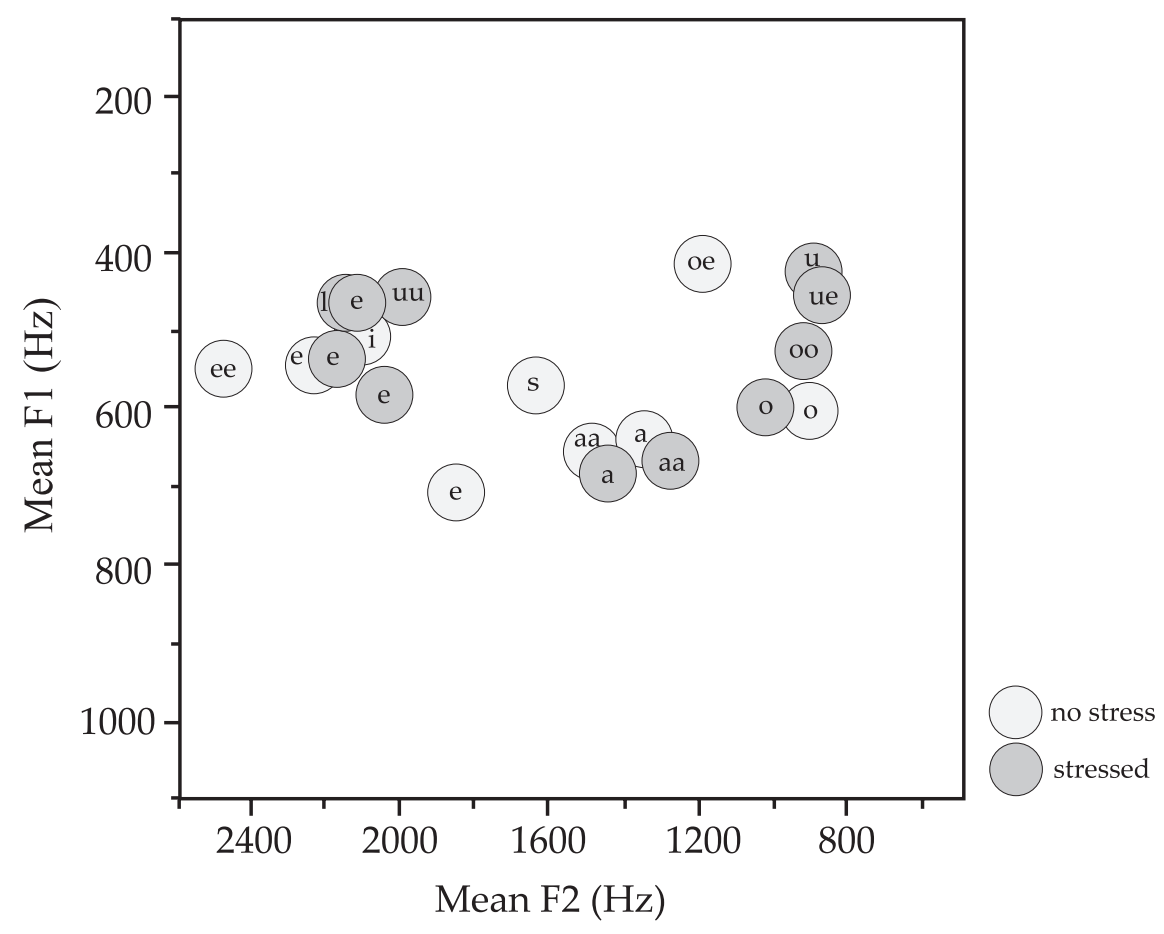

Figure 6a. Scatterplot of the Dutch monophthongs in stressed and unstressed condition, spoken by one male non-native speaker.

\section{CONCLUSION}

In this research, I investigated the way in which Indonesian students pronounce Dutch vowels. I wanted to find out to what extent the pronunciation of nonnative speakers differs from the speech of native speakers of Dutch. My main interest was the realization of Dutch stressed versus unstressed vowels, with focus on the duration and the quality of the vowels.

The way in which the non-native speakers realized vowel duration differed in general not significantly from the native speakers' pronunciation. Differences occurred only in a few cases. To start with, a difference occurred due to the wrong stress position, that is, non-native speakers sometimes pronounced the schwa vowel with stress, which is not correct; schwa is never stressed in Dutch. In addition, non-native speakers realized the / / (u) significantly longer in unstressed than in stressed condition. On the other hand, the non-native and the native speakers realized tense-lax distinctions 


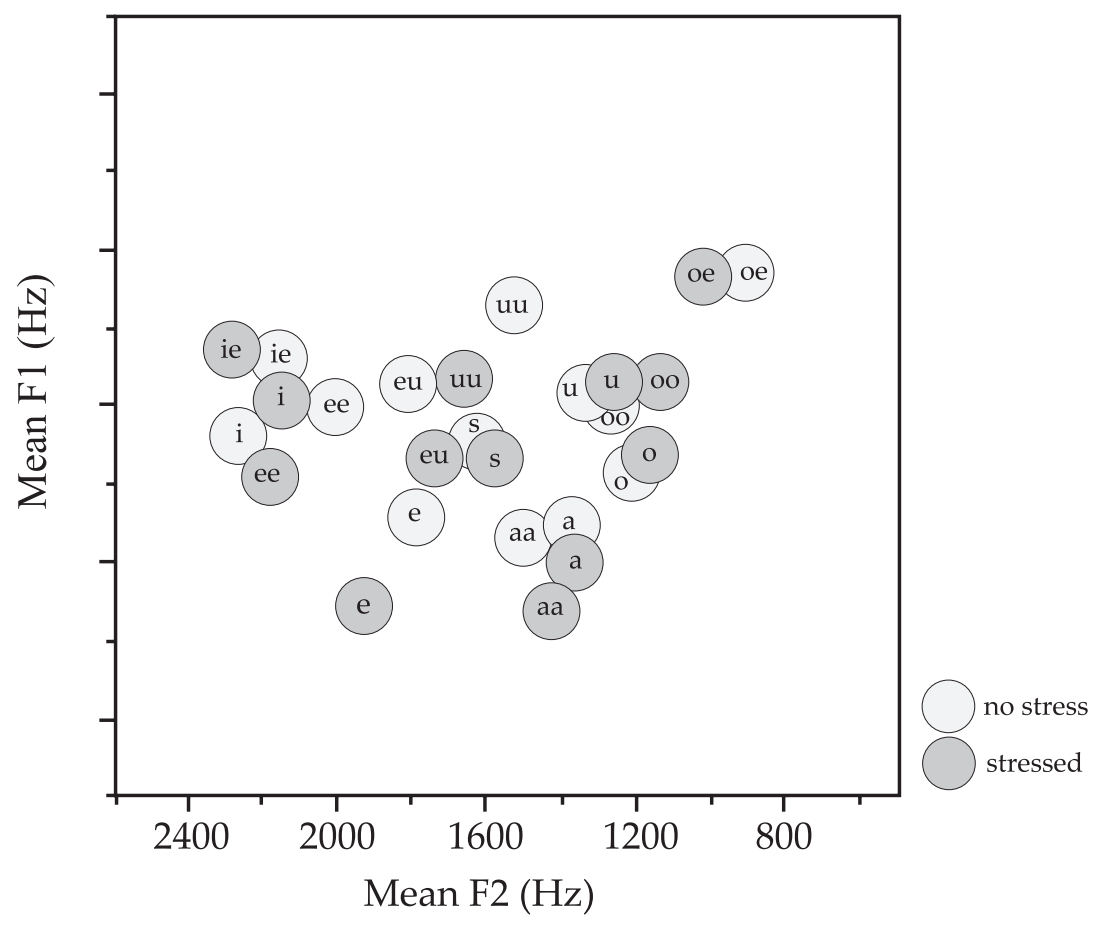

Figure 6b. Scatterplot of the Dutch monophthongs in stressed and unstressed condition, spoken by two female non-native speakers.

in almost the same way. However, accentual lengthening was stronger by the non-native speakers than by the native speakers. This last finding corresponds to Roosman (2006).

The quality of the Dutch vowels spoken by the non-native speakers differs to some extent from the vowel quality of the native Dutch speakers. The Indonesian students realized the vowels in general more open than the Dutch native speakers did. That there are no significant differences between the F1 and F2 values of the stressed and unstressed vowels in general, suggests that our non-native subjects found it hard to differentiate between the realizations of stressed and unstressed vowels as regards quality. They did articulate the vowels slightly more clearly when stressed than when not stressed, but the difference between stressed and unstressed vowel tokens by the Dutch native speakers is obviously larger. If we compare the scatterplots of both groups of speakers, it can be said that the Dutch vowel space as used by the Indonesian students is smaller than that of the Dutch native speakers.

The realization of Dutch stressed vowels by the Indonesian students is probably influenced by the durational structure of their mother tongue. The Indonesian students of Dutch realized stressed vowels with more lengthening than the Dutch native speakers did. This may be because length is not a distinctive feature in Indonesian: it does not differentiate one vowel from another, as is the case with the lax (short) vowels and their tense (long) 
counterparts in Dutch. The way in which phrasal accents are realized in Indonesian may also play a role here. Lastly, Indonesian students produced a smaller vowel space than the Dutch natives did, most likely because Indonesian does not have as many vowels as Dutch. Indonesian speakers need less space to accommodate the six vowels of their native language, which probably was the cause why they pronounced the Dutch vowels rather close together.

Finally, Indonesian students need to learn more about how to realize stress in Dutch. It is not always necessary to pronounce stressed vowels with extreme lengthening, but it is better to pronounce stressed vowels more clearly compared to vowels that are not stressed.

\section{REFERENCES}

Bergem, D.R. van. 1993. "Acoustic vowel reduction as a function of sentence accent, word stress, and word class", Speech Communication 12: 1-23.

Berinstein, A.E. 1979. "A cross-linguistic study on the perception and production of stress". [UCLA Working Papers in Phonetics 47, University of California, Los Angeles.]

Boersma, P. and D. Weenink. 1996. "Praat, a system for doing phonetics by computer". [Report of the Institute of Phonetic Sciences 136, University of Amsterdam.]

Cambier-Langeveld, T. 2000. Temporal marking of accent and boundaries. Utrecht: Landelijke Onderzoekschool Taalwetenschap (LOT). [LOT dissertation series 32.]

Chun, Dorothy M. 2002. Discourse intonation in L2; From theory and research to practice. Amsterdam: John Benyamin.

Ham, E, W.H.T.M. Tersteeg, and L. Zijlmans, 2005. Help! Helpt u mij even? Een cursus Nederlands voor anderstaligen 2. Utrecht: Nederlands Centrum Buitenlanders.

Heuven, V.J. van. 2002. Boven de klanken. Amsterdam: Koninklijke Nederlandse Academie van Wetenschappen.

Kooij, Jan and Marc van Oostendorp. 2003. Fonologie; Uitnodiging tot de klankleer van het Nederlands. Amsterdam: Amsterdam University Press.

Ladefoged, Peter. 1982. A course in phonetics. New York: Harcourt Brace Jovanovich.

Mansur, Muslich. 2008. Fonologi bahasa Indonesia tinjauan deskriptif sistem bunyi bahasa Indonesia. Jakarta: Bumi Aksara.

Moeliono, A.M. and S. Dardjowidjojo. 1988. Tata Bahasa Baku Bahasa Indonesia. Jakarta: Balai Pustaka.

Pols, L. C. W. 1977. "Spectral analysis and identification of Dutch vowels in monosyllabic words". PhD thesis, Vrije Universiteit Amsterdam.

Pols, L.C.W., H.C.R. Tromp, and R. Plomp. 1973. "Frequency analysis of Dutch vowels from 50 male speakers", Journal of the Acoustical Society of America 53: 1093-1101.

Rietveld, A.C.M. and V.J. van Heuven. 1997. Algemene fonetiek. Bussum: Coutinho. 
Roosman, L. 2006. Phonetic experiments on the word and sentence prosody of Betawi Malay and Toba Batak. Utrecht: Landelijke Onderzoekschool Taalwetenschap (LOT).

Verhoeven, J. and C. van Bael. 2002. "Akoestische kenmerken van de Nederlandse klinkers in drie Vlaamse regio's", Taal en tongval 54: 1-23.

Wijngaarden, S.J. van. 2001. "Intelligibility of native and non-native Dutch speech", Speech Communication 35: 103-113.

Zanten, Ellen van. 1989. Vokal-vokal bahasa Indonesia; Penelitian akustik dan perceptual. Jakarta: Balai Pustaka.

Wang, Hongyan. 2007. English as a lingua franca; Mutual intelligibility of Chinese, Dutch and American speakers of English. Utrecht: Landelijke Onderzoekschool Taalwetenschap (LOT). [LOT dissertation series 147.] 